\title{
An engineering approach to fatigue analysis based on elastic-plastic fracture mechanics
}

\author{
J. Eufinger \\ Fraunhofer Institute for Structural Durability and System Reliability LBF, Darmstadt (Germany) \\ jens.eufingen@lbffraunhofer.de
}

\author{
A. Heinrietz, T. Bruder, H. Hanselka \\ Fraunhofer Institute for Structural Durability and System Reliability LBF, Darmstadt (Germany)
}

\begin{abstract}
Nowadays cast iron components are widely used in highly stressed structures. Component lifetime is strongly influenced by inhomogeneities caused by the material's microstructure and the manufacturing process (graphite particles, (micro-)shrinkage pores, inclusions). Inhomogeneities often act as a fatigue crack starter. Lifetime until failure may be divided into stages for crack initiation, short and long crack growth. Initiation of a crack of technical size $(\mathrm{a} \approx 1 \mathrm{~mm})$ is often dominated by the growth of short cracks. The paper presents an approach to analyze the mechanically short fatigue crack growth based on elastic-plastic fracture mechanics. The application of the approach is successfully demonstrated for cast iron material EN-GJS-400-18-LT using data from fatigue tests, microstructure and fracture surface analyses to assess the fatigue life.
\end{abstract}

KEYWORDS. cast iron, casting defects, fatigue life assessment, fracture mechanics, short crack behaviour

\section{INTRODUCTION}

$\mathrm{N}$ owadays cast iron components are produced with a very high casting quality due to constant enhancement of the casting processes. Nevertheless, it is not completely possible to exclude inhomogeneities (e.g. graphite particles, (micro-)shrinkage pores, inclusions) caused by the material's microstructure or the manufacturing process. Loading in the low cycle fatigue (LCF) range may occur in components as a result of real and/or design-related special and misuse events as well as braking and start-stop operations. Assessment of the components requires knowledge of the monotonic and cyclic stress-strain curve and the strain-life curve [1]. These material properties are typically determined in unnotched specimens without a defined starting crack. Small inhomogeneities, however, may already be present at the outset and grow throughout a large proportion of the test's lifetime.

The crack propagation under cyclic loading may be divided into three stages [2]. In stage 1 of the microstructurally short cracks, their growth is heavily influenced by the local microstructure and cannot be described using fracture mechanics approaches from the continuum mechanics point of view. Delay and acceleration phases alternate. Stage 2 is characterized by the growth of mechanically short cracks. It is impossible to disregard the plastic zone size at the crack tip in relation to the crack's dimensions. The result is plasticity-dependent enhancement of the crack tip loading. Although it may be described from the continuum mechanics point of view, it cannot be described adequately on the basis of linear-elastic fracture mechanics. In this stage of crack growth too, the plasticity-induced crack closure effect has not yet developed fully since the defect has no prehistory of plastic deformation at the outset. In the final stage, the long crack extends until 
ultimate failure of the cracked structure. Long crack growth, with the exception of the high strain amplitudes present in the LCF range, can be described using linear-elastic fracture mechanics approaches.

Experimental studies on cast materials [3 - 6] have shown that in the LCF range both the crack formation phase starting from an inhomogeneity and also the long crack growth phase have a lower percentage share in the overall lifetime. A substantial part of the overall lifetime is determined by the growth of short cracks starting from an inhomogeneity on or close to the surface of the specimen. It is for this reason that understanding the mechanisms of short crack growth is very helpful for describing fatigue processes. Knowledge of the short crack behaviour may be significant particularly for components that are predominantly loaded at a lower stress level with more than $10^{6}$ cycles (HCF) and in which the formation of short cracks starts relatively early in the lifetime due, for example, to extreme load events. Results obtained from fatigue tests are always affected by scattering. It is interesting therefore to consider the material-specific and manufacture-specific inhomogeneities as a parameter in the fatigue life assessment and thus to be able to explain the scattering of the test results at least in part.

\section{MATERIAL PROPERTIES AND EXPERIMENTAL STUDIES}

7 he fatigue tests which are presented in this paper were conducted on specimens from two different casting variants (CV) of the ductile cast iron material EN-GJS-400-18-LT with dissimilar graphite morphology. The chemical compositions may be taken from Tab. 1 and the static material properties from Tab. 2. Fig. 1 illustrates the graphite morphology of the casting variants.

\begin{tabular}{|c|c|c|c|c|c|c|}
\hline & $\% \mathrm{C}$ & $\% \mathrm{Si}$ & $\% \mathrm{Mn}$ & $\% \mathrm{P}$ & $\% \mathrm{~S}$ & $\% \mathrm{Mg}$ \\
\hline CV 1 & 3.65 & 2.0 & 0.19 & 0.024 & 0.008 & 0.034 \\
\hline CV 2 & 3.58 & 2.09 & 0.17 & 0.031 & 0.006 & 0.03 \\
\hline
\end{tabular}

Table 1: Chemical composition [in wt.\%] of the materials

\begin{tabular}{cccccc} 
& Temp. $\left[{ }^{\circ} \mathrm{C}\right]$ & $\mathrm{R}_{\mathrm{m}}[\mathrm{MPa}]$ & $\mathrm{R}_{\mathrm{p} 0.2}[\mathrm{MPa}]$ & $\mathrm{A}[\%]$ & $\mathrm{Z}[\%]$ \\
\cline { 3 - 6 } CV 1 & 20 & 373 & 237 & 25.4 & 22.0 \\
CV 2 & 20 & 364 & 246 & 14.2 & 12.0 \\
\hline
\end{tabular}

Table 2: Mechanical properties of the materials

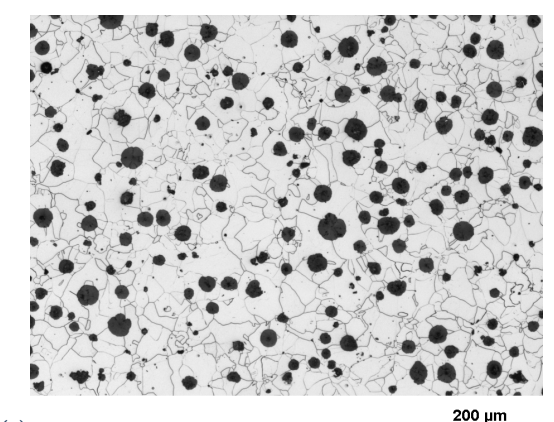

(a)

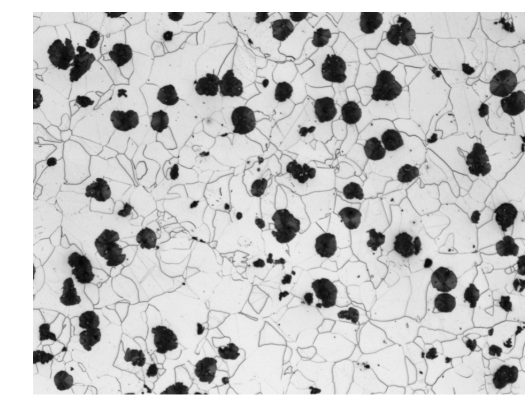

$\stackrel{200 \mu \mathrm{m}}{\longmapsto}$

(b)

Figure 1: Graphite morphology: material CV 1 (a) and material CV 2 (b)

The strain-controlled fatigue tests were performed with an axial tension-compression loading (strain ratio $\mathrm{R}_{\varepsilon}=-1$ ) on unnotched round specimens $\left(K_{t}=1\right)$ having a machined specimen surface. The monotonic and cyclic stress-strain curves were also determined from these tests at half the number of cycles to initiation of a crack of technical size. The elasticplastic material behaviour under cyclic loading can be well described using the Ramberg-Osgood equation (Fig. 2)

$$
\varepsilon=\frac{\sigma}{E}+\left(\frac{\sigma}{K^{\prime}}\right)^{\frac{1}{n^{\prime}}}=\frac{\sigma}{165000[M P a]}+\left(\frac{\sigma}{472[M P a]}\right)^{\frac{1}{0,0526}}
$$


The ferritic cast iron materials exhibit cyclic strain hardening in a known manner [1]. In the approach presented here, the material is considered to be cyclically stabilized.

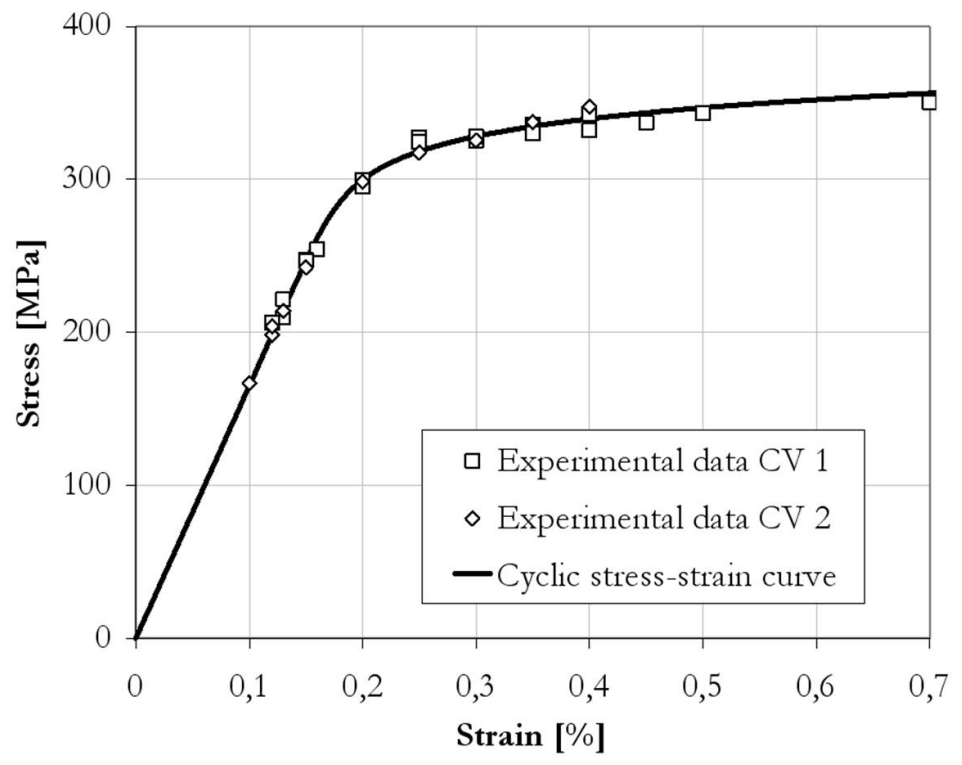

Figure 2: Cyclic stress-strain curve of the material.

Fatigue crack growth is mainly to be found starting from microshrinkage pores ranging in size from 60 to $500 \mu \mathrm{m}$ on or just under the specimen surface. It was possible to detect this inhomogeneities by means of fractographic studies subsequent to the fatigue tests. From the enveloping contours around the microshrinkage pores, each of the starting crack sizes of a semi-circular surface crack used in the approach is determined in accordance with the $\sqrt{\text { area }}$ - criterion according to Murakami [7]. The depth-to-length ratios of the porosity dimensions are always within the criterion's validity range.

\section{Elastic-PLASTIC FATIGUE CRACK GROWTH APPROACH}

\section{Basic principles}

he conditions of small scale yielding (SSY) are breached during the growth of mechanically short cracks and/or higher loading $[2,8,9,10]$. The application of conventional approaches of linear-elastic fracture mechanics is no longer adequate and may lead to non-conservative results in the fatigue life assessment. An appropriate crack tip parameter must be used as a substitute for the stress intensity factor. In the approach presented here, the effective Jintegral range considering crack closure effects is used to analyze the elastic-plastic crack growth

$$
d a / d n=C \cdot\left(\Delta J_{e f f}\right)^{m}
$$

Successful use in fatigue life assessment has already been documented in several publications, among others in [11] and [12]. The applicability of the cyclic J-integral is, however, a controversial issue since the necessary requirement of independence from the integration path is no longer strictly given under cyclic loading. The definition of the crack tip parameter, which ensures path independence even under cyclic loading, is explained in detail in [10] and [11]. The increments of the stresses and strains are explicitly included in the expression, that is

$$
\Delta J \neq J_{\max }-J_{\min }
$$

Moreover, the effective J-integral range $\Delta \mathrm{J}_{\text {eff }}$ is to be calculated from the descending hysteresis loop branch up to the crack closure point. It is known from studies on the crack closure behaviour of short cracks in [11] that crack opening and 
crack closure under elastic-plastic loading occurs at approximately the same strain value. The condition of identical crack opening and crack closure strains is also assumed in the approach presented here.

\section{Fatigue crack growth parameters}

Possible correlation of the fatigue crack growth of mechanically short cracks and long cracks using the effective J-integral range according to Eq. (2) is presented in [11] for various steels and a wrought aluminium alloy. Experimental studies [3, $4,6]$ also demonstrate good correlation of the crack growth data of mechanically short cracks with the long crack growth data determined with CT specimens at high stress ratios for the group of cast iron materials.

In the approach presented here, use is made of fatigue crack growth parameters obtained from experimental studies of the cyclic crack growth behaviour of a ductile cast iron EN-GJS-400-18-LT in [13]. The fatigue crack growth measurements were performed in accordance with ASTM E647-00 on a Mikrotron 20 resonance testing machine manufactured by the Rumul company. Three-point bend specimens having the dimensions $10 \mathrm{~mm}$ x $20 \mathrm{~mm}$ x $100 \mathrm{~mm}$ were used for the tests with constant stress ratios $\mathrm{R}=0.1,0.3$ and 0.5 . Crack depth measurement was performed using the compliance method. The experimentally determined crack growth rates were well approximated in [13] for various stress ratios $\mathrm{R}$ using the NASGRO Eq. [14]:

$$
\frac{d a}{d n}=C_{K}\left[\left(\frac{1-f}{1-R}\right) \cdot \Delta K\right]^{n} \frac{\left(1-\frac{\Delta K_{t h}}{\Delta K}\right)^{p}}{\left(1-\frac{K_{\max }}{K_{c}}\right)^{q}}
$$

an extended Paris-Erdogan equation which describes all three regions of the cyclic crack growth curve as a function of the stress ratio $\mathrm{R}$. The parameters of equation (4) may be taken from Table 3.

\begin{tabular}{cccccc}
\hline $\mathrm{C}_{\mathrm{K}}$ & $\mathrm{n}$ & $\mathrm{p}$ & $\mathrm{\Delta \textrm {K } _ { 0 }}$ & $\mathrm{K}_{\mathrm{c}}$ \\
$3.8 * 10^{-9}$ & 3.8 & 0.2 & in $\mathrm{MPa} \sqrt{\mathrm{m}}$ & in $\mathrm{MPa} \sqrt{\mathrm{m}}$ \\
\hline
\end{tabular}

Table 3: Parameters of the "NASGRO model" for EN-GJS-400-18-LT acc. to [13]

The effect of the stress ratio on the $\mathrm{da} / \mathrm{dn}-\Delta \mathrm{K}$ curve is conditional upon the effect of crack closure. In Eq. (4), the effective cyclic stress intensity factor at which the crack is open corresponds to an expression

$$
\Delta K_{\text {eff }}=\left(\frac{1-f}{1-R}\right) \cdot \Delta K
$$

The function $f=K_{o p} / K_{\max }$ is based on a model by Newman [15] which is widely used. Parameters $C_{K}$ and $n$ and threshold value $\Delta K_{\text {eff, th }}$ may be converted allowing for

$$
\Delta J_{e f f}=\frac{\Delta K_{e f f}^{2}}{E^{\prime}}
$$

into parameters $\mathrm{C}$ and $\mathrm{m}$ and threshold value $\Delta \mathrm{J}_{\text {eff,th }}$ of the crack growth law according to Eq. (2).

\section{Crack closure behaviour}

The experimental studies in [13] show that the effect of the stress ratio $\mathrm{R}$ on the growth of long cracks in the ductile cast iron material EN-GJS-400-18-LT may be described with sufficient accuracy by the function according to the model by Newman. The suitability of this function is also presented at higher maximum strains and stress ratios $-2<\mathrm{R}<1$ in [12]. 
The function also describes the experimentally confirmed correlation between the decreasing crack opening stresses with increasing load amplitude [11]. Thus, in the approach presented here, Newman's function is used to calculate the stabilized crack opening stresses with an equation modified by Vormwald [11] for calculating the average yield stress

$$
\sigma_{0}=0,5 \cdot\left(R_{p 0,2}^{\prime}+R_{m}\right)
$$

Short cracks, however, remain open over the entire stress and strain range of a cycle [11]. Experimental studies on the growth of short cracks starting from natural defects in ([3], [4], [6], [16]) also demonstrate this behaviour for the group of cast iron materials. In addition, the transient crack opening behaviour during the growth of short cracks is analyzed for a ferritic cast iron in [16] (Fig. 3) and a ferritic-perlitic cast iron in [6]. Short cracks which are initiated at inclusions, porosities, etc. have no a priori plastically deformed crack surface which might cause plasticity-induced crack closure. The crack opening stress therefore develops in a transient process up to the stabilized level measured in long cracks [17]. If a short crack is completely opened, the full stress and strain range is applied to calculate the cyclic J-Integral. As a result, the crack growth rate is higher than in long cracks with stabilized crack opening stress.

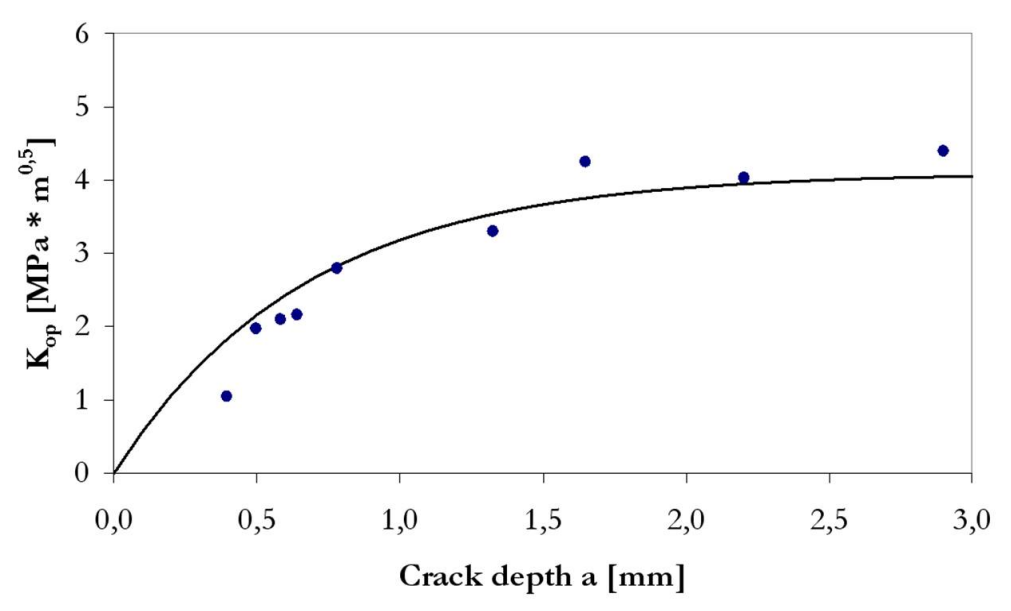

Figure 3: Transient short crack opening behaviour, data taken from [16].

The transient development of the crack opening behaviour may be described with a modification of the model by Newman to calculate the crack opening stress for short cracks based on a model by McEvily [18]. In the approach presented here,

$$
\sigma_{o p, t r}=\sigma_{U}+\left(\sigma_{o p}-\sigma_{U}\right) \cdot\left(1-\exp \left[-k_{\sigma} \cdot\left(a-a_{0}\right)\right]\right)
$$

is used to calculate the transient crack opening stress. The parameter $k_{\sigma}$ is a material-dependent characteristic value which where $k_{\sigma}=7$ enables an adequate approximation of Eq. (8) to the experimentally determined, transient crack opening behaviour from [16]. Using the cyclic stress-strain curve according to Eq. (1) and assumption of the Masing behaviour and identical crack opening and crack closure strains, $\sigma_{o p, t r}$ is used to calculate the transient crack opening and crack closure strain $\varepsilon_{o p, t r}$ and $\varepsilon_{c l, t r}$ as well as the crack closure stress $\sigma_{c l, t r}$.

\section{Crack tip parameter - numerical analyses and analytical solutions}

It is necessary to use analytical solutions to calculate the crack tip loading during an efficient fatigue crack growth analysis. In this approach, to calculate the J-integral for short semi-circular surface cracks in an unnotched round specimen, the frequently used formula by Dowling [19] is applied in a form modified according to Vormwald and Seeger [11] and allowing for the transient crack closure stresses and strains in addition to a Poisson's ratio $\mu=0,28$ 


$$
\Delta J_{e f f}=\left[1,26 \cdot \frac{\left(\sigma_{O}-\sigma_{c l, t r}\right)^{2}}{E}+\frac{1,02}{\sqrt{n^{\prime}}} \cdot\left(\sigma_{O}-\sigma_{c l, t r}\right) \cdot\left[\left(\varepsilon_{O}-\varepsilon_{c l, t r}\right)-\left(\frac{\sigma_{O}-\sigma_{c l, t r}}{E}\right)\right]\right] \cdot a
$$

The growth of semi-circular short cracks is also confirmed in experimental studies on cast iron materials [3, 6]. In the approach presented here, another analytical approximation solution was also determined comparatively to calculate the J-integral for short semi-circular surface cracks in an unnotched round specimen. This solution is based on a procedure according to Zerbst et al. [20]. For this purpose, three-dimensional, elastic and elastic-plastic finite element analyses of the round specimen with surface crack were performed for various crack depths a $(0.05 \mathrm{~mm}<\mathrm{a}<2 \mathrm{~mm})$ and a/c $=1$. The J-integral may be analytically approximated using flaw assessment procedures, such as R6 [21] and SINTAP/FITNET [22], which are based on the reference stress approach. In the reference stress approach, the quality of the approximation is essentially determined by the chosen limit load $\mathrm{F}_{\mathrm{Y}}$. Zerbst et al. suggest a modified procedure replacing the limit load $\mathrm{F}_{\mathrm{Y}}$ by a reference load $\mathrm{F}_{0}$. Its value is derived from the condition that the ligament yielding parameter

$$
L_{r}=\frac{\sigma_{r e f}}{\sigma_{Y}}=\frac{F}{F_{0}}
$$

in the function

$$
f\left(L_{r}\right)=\left[\frac{E \cdot \varepsilon_{r e f}}{L_{r} \cdot \sigma_{Y}}+\frac{L_{r}^{3} \cdot \sigma_{Y}}{2 \cdot E \cdot \varepsilon_{r e f}}\right]^{-1 / 2}
$$

is set at $L_{r}=1$. With $L_{r}=1$, Zerbst et al. chose a value at which significant plasticity occur but where assured determination of the J-integral is still possible using FE analyses and the results are relevant in practice. The materialdependent value for $f\left(L_{r}=1\right)$ is the result of equation (11) and corresponds to the ratio $J / J_{\text {el }}$ on reaching the reference load. Using the crack-length-dependent reference loads $F_{0, z y k l}$ determined, the effective J-integral range as

$$
\Delta J_{e f f}=\frac{\Delta K_{e f f}^{2}}{E^{\prime}} \cdot\left[f\left(\Delta L_{r, e f f}\right)\right]^{-2}
$$

where

$$
\Delta L_{r, e f f}=\frac{\Delta F_{e f f}}{2 \cdot F_{0, z y k l}}=\frac{\sigma_{O}-\sigma_{c l, t r}}{2 \cdot F_{0, z y k l}}
$$

is described analytically in the approach presented here. The geometry factors arising from the J-integral values of the elastic FE analyses were also calculated for the configurations of short cracks in a round specimen considered here. As expected, for short cracks ( $\leq 1 \mathrm{~mm}$ ), there is good correlation with the geometry factors for semi-elliptical surface cracks in a plate by Newman and Raju [23]. It may be assumed, therefore, that the stress intensity factors in Eq. (12) can be calculated with sufficient accuracy using the approximation formulae of Newman and Raju.

\section{APPLICATION AND CONCLUSION}

7 he results of applying the approach for the fracture mechanics-based analysis of the fatigue properties of a cast iron material EN-GJS-400-18-LT are presented in Fig. 4 compared to the cycles to initiation of a crack of technical size $(\mathrm{a} \approx 1 \mathrm{~mm})$ determined experimentally. 


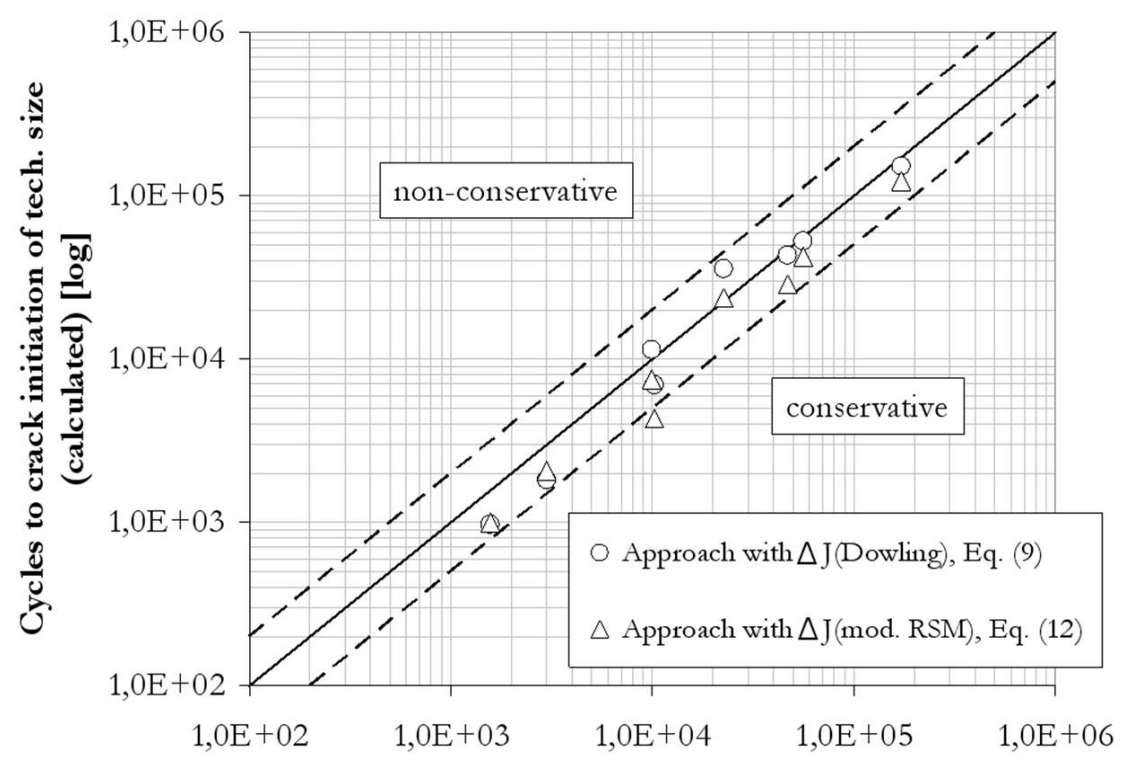

Cycles to crack initiation of tech. size (experimental) [log]

Figure 4: Comparison of test data with calculated cycles

If Eq. (9) according to Dowling is used in the approach to calculate the effective J-integral range, then the calculated number of cycles differs by no more than the factor $f_{\mathrm{N}}=1.6$ compared to the values determined experimentally. In some cases, however, the calculation results are non-conservative. When using the analytical solution to calculate the effective J-integral range according to Eq. (12) based on the reference stress approach and the modified procedure according to Zerbst et al., the calculated number of cycles differs by no more than 2.4 times the values determined experimentally. In this case, the calculation results are always conservative. In both cases, the transient crack opening and crack closure behaviour was taken into consideration in the approach. First of all, it can be seen that tendentially lower cycles to initiation of a crack of technical size are calculated using Eq. (12). Comparison with the numerical results from the FE analyses shows that the J-integral values calculated using Eq. (12) tend towards conservative values particularly at lower loading conditions. To sum up the calculated and the experimentally determined number of cycles correlate very well. The application of the approach based on mechanically short cracks growth is successfully demonstrated to analyze the fatigue testing results of an EN-GJS-400-18-LT.

\section{ACKNOWLEDGEMENT}

7 he fatigue tests were carried out by the Fraunhofer LBF in the course of the MABIFF research project. The chemical composition of the casting variants and their static material properties were determined by the Institute for Casting Technology (IfG), Düsseldorf. The authors would like to thank the Federal Ministry of Education and

Research (BMBF) for its financial support of the MABIFF research project (Grant No. 01RI0713A) and the Institute for Casting Technology (IfG) for providing the data.

\section{REFERENCES}

[1] C. M. Sonsino, V. Grubisic, Materialwissenschaft und Werkstofftechnik, 27 (8) (1996) 373.

[2] K. J. Miller, Fatigue \& Fracture of Engineering Materials \& Structures, 10 (1) (1987) 75.

[3] M. S. Starkey, P. E. Irving, In: Prediction of fatigue life of smooth specimens of SG iron by using a fracture mechanics approach, C. Amzallag, B. N. Leis, \& P. Rabbe (Eds.), ASTM STP 770 (1982) 382.

[4] C. Hua, Fatigue crack growth in nodular cast iron. Department of Mechanical and Industrial Engineering, University of Illinois at Urbana-Champaign, FCP report No. 47 (1983). 
[5] B. Skallerud, T. Iveland, G. Härkegard, Engineering Fracture Mechanics, 44 (6) (1993) 857.

[6] Y. Nadot, J. Mendez, N. Ranganathan, A. S. Beranger, Fatigue \& Fracture of Engineering Materials \& Structures, 22 (4) (1999) 289.

[7] Y. Murakami, Metal Fatigue - Effects of small defects and nonmetallic inclusions. Amsterdam, Boston, London u.a.: Elsevier Science Ltd. (2002).

[8] U. Zerbst, M. Schödel, M. Vormwald, Ermüdungsrissausbreitung. MP Materials Testing, 49 (3) (2007) S. 70.

[9] D. Davidson, K. Chan, R. C. McClung, S. Hudak, In: Comprehensive structural integrity, I. Milne, R. O. Ritchie, \& B. Karihaloo (Eds.):, Amsterdam, Boston, London u.a.: Elsevier Science Ltd. (2003).

[10] M. Vormwald, O. Hertel, G. Savaidis, In: DVM-Bericht, 239 (2007).

[11] M. Vormwald, Anrißlebensdauervorhersage auf Basis der Schwingbruchmechanik für kurze Risse, Institut für Stahlbau und Werkstoffmechanik, TU Darmstadt, Germany, Heft 47 (1989).

[12] R. C. McClung, G. G. Chell, Y. D. Lee, D. A. Russell, G. E. Orient, Development of a practical methodology for elastic-plastic and fully plastic fatigue crack growth. Report NASA/CR-199-209428, NASA, Springfield VA, USA, (1999).

[13] P. Hübner, G. Pusch, Zyklisches Risswachstumsverhalten von Gusseisenwerkstoffen - Analytische Aufbereitung für die Nutzung des Berechnungsprogramms „ESACRACK“. konstruieren + giessen, 32 (3) (2007) 34.

[14] NASGRO: Fatigue crack growth computer program NASGRO Version 3.0, Reference manual. JSC-22267B, NASA L.B. Johnson Space Centre, Houston, Texas, USA (2000).

[15] J. C. Newman JR., International Journal of Fracture, 24 (4) (1984) R131.

[16] P. Clement, J. P. Angeli, A. Pineau, Fatigue \& Fracture of Engineering Materials \& Structures, 7 (4) (1894) 251.

[17] J. C. Newman, JR., In: Comprehensive structural integrity, I. Milne, R. O. Ritchie, \& B. Karihaloo (Eds.), Amsterdam, Boston, London u.a.: Elsevier Science Ltd. (2003).

A. J. McEvily, M. Endo, Y. Murakami, Fatigue \& Fracture of Engineering Materials \& Structures, 26 (3) (2003) 269.

[18] N. E. Dowling, Engineering Fracture Mechanics, 26 (3) (1987) 333.

[19] U. Zerbst, A. Pempe, I. Scheider, R. A. Ainsworth, W. Schönfeld, Engineering Fracture Mechanics, 76 (1) (2009)74.

[20] R6: Assessment of the integrity of structures containing defects. British Energy Generation Ltd, Barnwood, Gloucester (2000).

[21] U. Zerbst, M. Schödel, S. Webster, R. A. Ainsworth, Fitness-for-Service fracture assessment of structures containing cracks. A workbook based on the european SINTAP/FITNET procedure. Amsterdam, Boston, London u.a.: Elsevier Science Ltd. (2007).

[22] J. C. Newman, JR., I. S. Raju, In: Computational methods in the mechanics of fracture, S. N. Atluri (Ed.), Amsterdam, Boston, London u.a.: Elsevier Science Ltd. (1986). 